\title{
Clinical Profile and Outcome of Acute Kidney Injury: A Prospective Cross-sectional Study at a Tertiary Hospital in Addis Ababa, Ethiopia
}

\author{
Merahi Kefyalew \\ Addis Ababa University \\ Aklilu Azazh \\ Addis Ababa University \\ Bekure Bewket Siraw ( $\nabla$ bekurebewkets15@gmail.com ) \\ Yekatit 12 Hospital Medical College \\ Amanuel Teklu \\ Addis Ababa University \\ Abdulkerim Seid \\ Addis Ababa University \\ Tesfaye Nigussie Admasu \\ Yekatit 12 Hospital Medical College
}

\section{Research Article}

Keywords: Acute Kidney Injury, Clinical Characteristics, Clinical Outcome, Prognosis, Mortality

Posted Date: June 16th, 2021

DOI: https://doi.org/10.21203/rs.3.rs-602149/v1

License: (c) (i) This work is licensed under a Creative Commons Attribution 4.0 International License. Read Full License 


\section{Abstract}

\section{Background}

Acute kidney injury (AKI) is a major health problem, causing morbidity in 13 million people annually, among which, $85 \%$ occur in developing countries. It is, therefore, one of the important issues in Africa where there is resource limitation at large, and appreciation of its pattern can help understand its causes, complications, and outcome better which are determinants for its early prevention and management. The objective of the study was to evaluate Patterns and outcomes of AKI patients who are admitted to the Tikur Anbessa specialized hospital (TASH) Adult Emergency Unit, Addis Ababa, Ethiopia.

\section{Methods}

A prospective Cross-sectional study was done from August 1, 2018, to May 1, 2019. . A total of 144 cases of AKI were included in the study. Binary logistic regression was done for the identification of mortality predictors. Patients' laboratory results on admission and discharge were compared by paired samples Ttest. Survival time was estimated by Kapan- Meier and Log Rank Test with a 95\% Cl.

\section{Results}

The mean age of presentation at a younger age of $46.16 \pm 16.6$, the most common causes of AKI were Sepsis (43.2\%), volume depletion (25\%), cardiorenal syndrome (16\%), and obstructive uropathy (16\%). Uremic encephalopathy, sepsis, and hyperkalemia were factors that were identified as mortality predictors in overall AKI patients.

\section{Conclusion}

AKI patients with sepsis were found to have lower hospital survival than those without sepsis. From the laboratory findings, there was a significant difference between creatinine values on admission and discharge.

\section{Background}

Acute kidney injury is defined as a decline in renal function over hours or days resulting in the accumulation of toxic wastes and the loss of internal homeostasis.

Acute kidney injury (AKI) is one of the major health problems, adversely affecting patient morbidity occurring in more than 13 million people every year, $85 \%$ of whom accounts for developing countries. (1) Several studies reviewed risk factors attributed to AKI, in terms of in-hospital mortality, progression to end-stage renal disease, accelerating the progression of established chronic kidney disease (CKD), and increased cardiovascular risk. (2) Yet quite a few data are addressing the epidemiology and causes of AKI in Low Resource Settings. (3-5) AKI with its related features accounts for around 3\% of admissions in general healthcare facilities. (6) 
In developing countries, the distinction between community-acquired and hospital-acquired AKI is important because AKI is commonly caused by community-acquired diseases such as dehydration secondary to acute gastroenteritis and malaria which can be easily prevented by community-based interventions like oral hydration. (7)

The etiology of AKI is classified into pre-renal, Intrinsic Renal, and Post Renal. It is known that AKI accounts for significant morbidity and mortality in the world, particularly in Africa. Yet there is insufficient data regarding its clinical profile in the Emergency unit in the tertiary center of Ethiopia. Therefore, it will be of paramount importance to do research on AKI which can clearly explain existing burden, common causes and risk factors, complications, practices of Management, and outcome. This can be acquired through acknowledging previous studies; determine the knowledge gap, and then filling the gap and guide by proving options in the way that healthcare professionals work.

AKI is one of the important issues in Africa particularly Ethiopia where there is resource limitation at large and appreciation of its local pattern can help inform policies on its early prevention and management.

This research is going to help understand common causes, complications, the practice of management, and outcomes of patients with AKI in our context by filling the knowledge gap in the area. Moreover, it will be one of the complements forwarded in solving problems regarding practices of management of AKI as it is going to have important implications regarding health promotion for a better life.

AKI is one of the common worldwide problems being responsible for an estimated 1.4 million deaths per year (8) and there are no trustworthy data regarding the incidence of AKI in Africa. According to regional publications, the incidence has been estimated at 150 per million populations. (6)

According to a systematic review (2004-2012) of large cohort studies conducted the pooled incidence rates of AKI were $21.6 \%$ in adults concluding that 1 in 5 adults worldwide experiences AKI during a hospital episode of care. (5)

Incidence of AKI in Low-income countries is not completely understood the proposed reasons being a late presentation of patients to tertiary centers, underreporting, and a reduced capacity to provide intensive care to severely ill patients. (9)

\section{Methods}

The study was a prospective cross-sectional study conducted from September 2018 to May 2019 in TASH, Addis Ababa, Ethiopia. The study included 144 patients. All AKI patients with age $\geq 13$ are included except those who opt-out and patients with CKD without superimposed AKI. Data were collected from charts using standardized forms. It was then processed and analyzed using SPSS software version 25. Categorical data were compared with the chi-square test. Mortality predictors were analyzed using binary logistic regression. Laboratory tests on admission and discharge were compared using paired samples Ttest. Kaplan- Meier estimator and Log Rank test with a confidence interval of $95 \%$ were used to assess 
survival of AKI patients with sepsis; who underwent dialysis; and those with underlying CKD. The time to discharge of each type of AKI was analyzed using the Kaplan-Meier curve. P-value $<0.05$ was considered significant.

\section{Results}

\section{Socio-demographics}

There were a total of 144 patients diagnosed to have AKI in the TASH Emergency Department from August 2018 to May 2019, 79 (54.9\%) of which were males, and the rest were female.The mean age of the patients was $46.6 \pm 16.6$ and around $40 \%$ of the patients are found in the age group between 30-50 years. Although patients came from all around Ethiopia, nearly half of them (49.3\%) came from Addis Ababa and more than a quarter of the patients came from Oromia (27.8\%). (Table 1 )

Table 1 Socio-demographic characteristics of patients with AKI, TASH, Addis Ababa, May 2019 


\section{Sociodemographic Sub-variable Frequency Percent}

\section{Variable}

\begin{tabular}{|c|c|c|c|}
\hline \multirow[t]{3}{*}{ Sex } & Male & 79 & 54.9 \\
\hline & Female & 65 & 45.1 \\
\hline & Total & 144 & 100 \\
\hline \multirow[t]{8}{*}{ Age } & $<21$ & 9 & 6.3 \\
\hline & $21-30$ & 20 & 13.9 \\
\hline & $31-40$ & 28 & 19.4 \\
\hline & $41-50$ & 29 & 20.1 \\
\hline & $51-60$ & 28 & 19.4 \\
\hline & $61-70$ & 18 & 12.5 \\
\hline & $>70$ & 12 & 8.3 \\
\hline & Total & 144 & 100 \\
\hline \multirow[t]{7}{*}{ Region } & Addis Ababa & 71 & 49.3 \\
\hline & Oromia & 40 & 27.8 \\
\hline & SNNPR & 16 & 11.1 \\
\hline & Amhara & 9 & 6.3 \\
\hline & Others & 6 & 4.2 \\
\hline & Total & 142 & 98.6 \\
\hline & Missing & 2 & 1.4 \\
\hline
\end{tabular}

\section{Clinical characteristics of AKI}

The commonest cause of AKI identified was sepsis (43.8\%), (Table 2) 39(27.1\%) of the patients were found to have preexisting CKD. The main underlying cause of CKD was extra-renal OUP which included $1 / 4^{\text {th }}$ of the cases $(25.6 \%)$ followed by hypertension $(23.1 \%)$ and diabetes $(20.5 \%)$. The mean baseline creatinine was $9.8 \pm 6.6$. The majority of deaths in AKI on CKD patients was found in those with extrarenal obstructive uropathy most of which are due to cervical ca. (38.5\%). (Table 2)

More than half, $52.8 \%$, of the patients with AKI had complications. Of these, the commonest complication identified was uremic encephalopathy which occurred in $42.1 \%$, followed by anemia (40.8\%) and hyperkalemia (28.9\%). 
A Chi-square test of independence was calculated comparing the frequency of clinical characters in men and women. A significant interaction was found in men with nephrolithiasis as compared with women

Table 2 Clinical characters and proportion of death of patients with AKI, TASH, Addis Ababa, 2019

\begin{tabular}{|c|c|c|c|c|c|c|}
\hline & $\begin{array}{l}\text { Clinical } \\
\text { characteristics }^{a}\end{array}$ & $\begin{array}{l}\text { Frequency } \\
\mathrm{N}(\%)\end{array}$ & $\begin{array}{l}\text { Male } \\
N(\%)\end{array}$ & $\begin{array}{l}\text { Female } \\
\mathrm{N}(\%)\end{array}$ & $\begin{array}{l}\mathrm{P} \text { - } \\
\text { Value }\end{array}$ & $\begin{array}{l}\text { Proportion } \\
\text { of } \\
\text { death(\%) }\end{array}$ \\
\hline \multirow[t]{9}{*}{ Causes of AKI } & Sepsis & $65(43.2)$ & $36(55.4)$ & $29(44.6)$ & 0.854 & $25(56.8)$ \\
\hline & Volume depletion & $36(25)$ & $19(52.8)$ & $17(47.2)$ & 0.805 & 12(27.3) \\
\hline & CRS-1 & 23((16) & $13(56.5)$ & $10(43.5)$ & 0.835 & $3(6.8)$ \\
\hline & OUP & $23(16)$ & $11(47.8)$ & $12(52.2)$ & 0.480 & $9(20.5)$ \\
\hline & AGN & $8(5.6)$ & $5(63)$ & $3(37)$ & 0.642 & $3(6.8)$ \\
\hline & Hypertensive crisis & $7(4.9)$ & $4(57.14)$ & $3(42.86)$ & 0.887 & $2(4.5)$ \\
\hline & Drug & $5(3.5)$ & $3(60)$ & $2(40)$ & 0.803 & $0(0)$ \\
\hline & TLS & $4(2.8)$ & $1(25)$ & $3(75)$ & 0.229 & $2(4.5)$ \\
\hline & Others & $3(2)$ & $3(100)$ & $0(0)$ & 0.194 & $1(2.3)$ \\
\hline \multirow{5}{*}{$\begin{array}{l}\text { Causes } \\
\text { Of underlying } \\
\text { CKD }\end{array}$} & Extra renal OUP & $10(25.6)$ & $4(40)$ & $6(60)$ & 0.349 & $5(38.5)$ \\
\hline & Hypertension & $9(23.1)$ & $6(66.7)$ & $3(33.3)$ & 0.462 & $3(23.08)$ \\
\hline & Diabetes & $8(20.5)$ & $5(62.5)$ & $3(37.5)$ & 0.655 & $3(23.08)$ \\
\hline & Nephrolithiasis & $5(12.8)$ & $5(100)$ & $0(0)$ & 0.039 & $0(0)$ \\
\hline & Others & $7(18)$ & $4(57.14)$ & $3(42.86)$ & 0.901 & $2(15.38)$ \\
\hline \multirow{6}{*}{$\begin{array}{l}\text { Complications } \\
\text { of AKI }\end{array}$} & $\begin{array}{l}\text { Uremic } \\
\text { encephalopathy }\end{array}$ & $32(42.7)$ & $20(13.9)$ & $12(8.3)$ & & $23(52.3)$ \\
\hline & Anemia & $31(41.3)$ & 15(10.4) & 16(11.1) & & 8(18.12) \\
\hline & Hyperkalemia & $22(29.3)$ & 10(6.9) & $12(8.3)$ & & $11(0.25)$ \\
\hline & Fluid overload & $11(14.7)$ & $7(63.64)$ & $4(36.36)$ & & $6(13.64)$ \\
\hline & Uremic gastropathy & $11(14.7)$ & $6(54.55)$ & $5(45.45)$ & & $3(6.82)$ \\
\hline & Uremic pericarditis & $3(4.0)$ & $3(100)$ & $0(0)$ & & $1(2.27)$ \\
\hline
\end{tabular}




\section{Laboratory values}

The patients had complete blood count and renal function tests during admission and upon discharge. The mean white cell count is $13,138.8 \pm 9558.1$ and $11810 \pm 6520.7$ on admission and discharges respectively. There is a good decrement of creatinine upon discharge from a mean of $5.7 \pm 5.4$ to $4.9 \pm 4.9$. (Table 3)

Table 3: Selected laboratory values of patients with AKI, TASH, Addis Ababa, 2019

\begin{tabular}{|lll|}
\hline Laboratory values & Point in time & Mean \pm Standard deviation \\
\hline Urea & Admission & $122 \pm 76.3$ \\
\cline { 2 - 3 } & \multicolumn{1}{|c|}{ Discharge } & $116.2 \pm 82.4$ \\
\hline Creatinine & Admission & $5.7 \pm 5.4$ \\
\cline { 2 - 3 } & Discharge & $4.9 \pm 4.9$ \\
\hline Hemoglobin & Admission & $13138.8 \pm 9558.1$ \\
\cline { 2 - 3 } & Discharge & $11810 \pm 6520.7$ \\
\hline Platelet count & Admission & $11.1 \pm 3.3$ \\
\cline { 2 - 3 } & Discharge & $10.8 \pm 2.9$ \\
\hline & Admission & $212887.4 \pm 127867.3$ \\
\hline
\end{tabular}

\section{Treatment practice and outcome of patients with AKI}

More than $3 / 4^{\text {th }}$ of the patients $(82.6 \%)$ took drug treatments for a variety of causes of AKI including cardiac, Septic ATN, hypertension, and AGN. On the other hand, around half of the patients took fluid treatment for the AKI.

18 patients (12.5\%) underwent dialysis. (Figure 1) ) Indications for dialysis are shown in Table 5 . The commonest indication identified was uremic encephalopathy $(72.2 \%)$ followed by hyperkalemia (27.8\%) and refractory fluid overload (22.2\%).

The rest minority underwent surgical management, percutaneous nephrostomy being the commonest surgical procedure. Cervical cancer was the cause in most cases of obstructive uropathy. 
The average duration of hospital stay was 7.2 days, the minimum being 2 days and the maximum is 36 days, with a range of 34 days. (Table 6 ) More than half of the patients (61.1\%) were discharged home. And nearly $1 / 3^{\text {rd }}(30.6 \%)$ of the patients died. 4 patients were referred to other centers the reason being lack of bed and two patients self-discharged against medical advice. (Figure 2)

Table 4: Indication for dialysis of AKI patients, TASH, Addis Ababa, 2019

\begin{tabular}{|lllllll|}
\hline & \multicolumn{5}{c|}{ Dialysis $^{\text {b }}$} & \multicolumn{3}{l|}{ Death } \\
\hline Indications for dialysis & & Yes(\%) & No(\%) & Total(\%) & Yes(\%) & No(\%) \\
\hline $\begin{array}{l}\text { Refractory } \\
\text { fluid overload }\end{array}$ & Yes(\%) & $4(22.2)$ & $7(5.6)$ & $11(7.7)$ & $6(60)$ & $4(40)$ \\
\hline Hyperkalemia & No(\%) & $14(77.8)$ & $117(94.4)$ & $131(92.3)$ & $38(29.7)$ & $90(70.3)$ \\
\cline { 2 - 7 } & Yes(\%) & $5(27.8)$ & $17(13.7)$ & $22(15.5)$ & $11(55)$ & $9(45)$ \\
\hline Uremic encephalopathy & yes(\%) & $13(72.2)$ & $107(86.6)$ & $120(84.5)$ & $33(28)$ & $85(72)$ \\
\cline { 2 - 7 } & No(\%) & $5(27.8)$ & $106(85.5)$ & $111(78.2)$ & $21(19.6)$ & $86(80.4)$ \\
\hline
\end{tabular}

${ }^{b}$ Sum is more than $100 \%$ as most patients had more than one indication for dialysis

Table 5: mean hospital LOS in each type of AKI, TASH, Addis Ababa, 2019

\begin{tabular}{|ll|}
\hline Types of AKI & Mean hospital LOS \pm SE \\
\hline Prerenal & $6.50 \pm 6.65$ \\
\hline Intrinsic renal & $7.84 \pm 8.18$ \\
\hline Post renal & $8.39 \pm 6.73$ \\
Mixed & $6.40 \pm 4.85$ \\
\hline
\end{tabular}

Common complications leading to deaths encountered were uremic encephalopathy, fluid overload, and hyperkalemia. From the death records, nearly $3 / 4^{\text {th }}(74.2 \%)$ had uremic encephalopathy; whereas in $60 \%$ of deaths, there were complications of fluid overload. And more than half of the deaths $(55 \%)$ had hyperkalemia. (Table 5)

\section{Predictors of mortality}

Binary logistic regression was implemented further to determine the independent predictors of mortality among AKI patients with and without CKD; In overall AKI patients (those AKI regardless of presence or absence of CKD) mortality was significantly correlated with the presence of Uremic encephalopathy 
$[\mathrm{OR}, 0.061 ; 95 \% \mathrm{Cl}(0.019,0.198) ; \mathrm{P}=<0.001]$ and hyperkalemia which was marginally significant $[\mathrm{OR}, 0.283$; $95 \% \mathrm{Cl}(0.077,1.046) ; \mathrm{P}=0.058]$. (Table 7)

Table 6: Binary logistic regression analyses for correlation between different factors and death in Overall as well as pure AKI (Without underlying CKD), TASH, Addis Ababa, 2019

\begin{tabular}{|c|c|c|c|c|c|}
\hline & & Death & & & \\
\hline & & $\operatorname{COR}(95 \% \mathrm{Cl})$ & $\begin{array}{l}\mathrm{P}- \\
\text { value }\end{array}$ & AOR(95\%Cl) & $\begin{array}{l}\text { P- } \\
\text { Value }\end{array}$ \\
\hline \multirow{5}{*}{$\begin{array}{l}\text { factors in } \\
\text { AKI }\end{array}$} & Fluid Overload & $3.55(0.95,13.3)$ & 0.060 & $1.743(0.28,10.68)$ & 0.548 \\
\hline & Hyperkalemia & $3.15(1.19,8.29)$ & 0.02 & $5.06(1.291,19.87)$ & 0.020 \\
\hline & Sepsis & $2.46(1.18,5.16)$ & 0.017 & $3.151(1.23,8.07)$ & 0.017 \\
\hline & $\begin{array}{l}\text { Uremic } \\
\text { encephalopathy }\end{array}$ & $11.8(4.6,30)$ & $<0.001$ & $13.71(4.32,43.5)$ & $<0.001$ \\
\hline & $\begin{array}{l}\text { Creatinine on } \\
\text { admission }\end{array}$ & $0.952(0.893,1.014)$ & 0.128 & $1.049(0.954,1.154)$ & 0.320 \\
\hline \multirow{5}{*}{$\begin{array}{l}\text { Factors } \\
\text { In } \\
\text { AKI without } \\
\text { underlying } \\
\text { CKD }\end{array}$} & Fluid overload & $3.12(0.67,15.32)$ & 0.144 & $1.189(0.090,15.627)$ & 0.895 \\
\hline & Hyperkalemia & $6.32(1.51,26.44)$ & 0.012 & $0.124(0.017,0.905)$ & 0.039 \\
\hline & Sepsis & $2.31(0.96,5.54)$ & 0.062 & $0.378(0.124,1.152)$ & 0.087 \\
\hline & $\begin{array}{l}\text { Uremic } \\
\text { encephalopathy }\end{array}$ & $30.93(6.4,149.19)$ & $<0.001$ & $0.033(0.006,0.190)$ & $<0.001$ \\
\hline & $\begin{array}{l}\text { Creatinine on } \\
\text { admission }\end{array}$ & $0.90(0.811,0.999)$ & 0.047 & $1.036(0.887,1.211)$ & 0.653 \\
\hline
\end{tabular}

A paired-samples t-test was conducted to compare selected laboratory values of patients with AKI upon admission and discharge. There was a significant difference between creatinine values upon admission $(M=5.14, S D=4.9)$ and discharge $(M=4.87, S D=4.85)$ conditions; $t(46)=3.243, p=0.002$. These results showed that there was a real improvement in creatinine after the patient finished the course in the hospital. (Table 8)

Table 7: Paired-samples T-test for selected laboratory values of patients with AKI, TASH, Addis Ababa,2019 


\begin{tabular}{|c|c|c|c|c|c|c|c|c|}
\hline \multirow{2}{*}{$\begin{array}{l}\text { Laboratory } \\
\text { values on } \\
\text { admission } \\
\text { and } \\
\text { discharge }\end{array}$} & \multirow[t]{2}{*}{ Mean } & \multirow[t]{2}{*}{ SD } & \multirow[t]{2}{*}{$\begin{array}{l}S E \\
\text { means }\end{array}$} & \multicolumn{2}{|c|}{$\begin{array}{l}95 \% \mathrm{Cl} \text { of the } \\
\text { difference }\end{array}$} & \multirow[t]{2}{*}{$t$} & \multirow[t]{2}{*}{ df } & \multirow{2}{*}{$\begin{array}{l}\text { Sig. } \\
(2- \\
\text { tailed) }\end{array}$} \\
\hline & & & & Lower & Upper & & & \\
\hline Urea & 15.561 & 52.164 & 9.369 & -3.573 & 34.695 & 1.661 & 30 & 0.107 \\
\hline Creatinine & 1.067 & 2.256 & 0.329 & 0.405 & 1.730 & 3.243 & 46 & 0.002 \\
\hline WBC & 1862.750 & 7816.859 & 1235.954 & -637.203 & 4362.703 & 1.507 & 39 & 0.140 \\
\hline Hemoglobin & -0.0111 & 2.953 & 0.479 & -1.081 & 0.860 & -0.231 & 37 & 0.819 \\
\hline
\end{tabular}

\section{Survival of AKI patients}

Probability of survival of AKI patients who have sepsis, who underwent dialysis and who had underlying CKD estimated using Kaplan-Meier curves, a lower survival of all AKI patients with sepsis over the hospital stay period was found with marginally significant P-value (Mean survival AKI with sepsis=16.967; $S E=3.169$ vs. without sepsis=28.105; SE 3.413; $P=0.056$ ). The comparison between AKI patients with CKD, time to death didn't significantly differ from those who haven't underlying CKD., For those patients who underwent dialysis, as is, no significance with regards to survival in-hospital stay. Finally, time to discharge was assessed between each type of AKI and there was no significant difference found. (Figure 3)

\section{Discussion}

This study elucidated the epidemiology, causes, complication practice of management, and outcomes of patients with AKI. The presentation of the patients at a younger age coincided with results from Europe, African countries as well as those done in Ethiopia. $(10,11)$

Although patients coming from different corners of the country, more than half of the patients came from Addis Ababa and Oromia, this coincides with another literature done in St. Paul hospital which is found in the same area where TASH is found. (11) This can be explained by the geographical proximity of the patients living in Addis Ababa and Oromiya to TASH.

In line with the study done in the sub-Saharan country,(12) ATN was the leading cause of AKI in this study, followed by gastrointestinal loss(diarrhea or vomiting), cardiac and obstructive uropathy. In contrast, recent local literature from Saint Paul's Hospital Millennium Medical College showed that the predominant causes were hypovolemia, acute glomerulonephritis, and pregnancy-related causes. (11) 
Sepsis-related AKI was the top cause on the list in this study. This went in harmony with the study done across Australia which showed that nearly $1 / 3^{\text {rd }}$ of patients with AKI had sepsis. (13) However, the study done in Uganda showed a considerably lower number of septic-related AKI cases which was $16.3 \%$.(14)

This study showed that CRS-1 is still one of the major causes of AKI which was also strengthened by a systematic review and meta-analysis. (15) Yet, there is a difference regarding the dominant cause of CRS1 which in this study is acute heart failure in contrast to a single-center retrospective study done in the USA which showed that acute coronary syndrome to be the dominant cause of CRS-1. (16) This dissimilarity can be explained by the higher incidence of valvular heart disease in Ethiopia as compared to the western setup.

OUP was also found to be one of the major causes of AKI which corresponds to reports from other African countries. And the major cause of OUP was women with cervical ca. which is still consistent with other developing countries. (17)

AGN accounted for $5.6 \%$ of all AKI cases admitted to the hospital with higher mortality of $37.7 \%$ as compared to other causes and this closely correlated with the report from Pakistan which showed $4.19 \%$ which also unfolded that the morbidity was higher in comparison with other causes. (18)

Counter to the data from Capetown which demonstrated that exogenous nephrotoxins accounted for more than $1 / 3^{\text {rd }}(37.4 \%)$ of AKI patient,(2) this study showed that they were one of the rare causes of AKI

In this study, more than half of the patients with AKI were discharged and nearly $1 / 3^{\text {rd }}$ died, both findings being consistent with other local literature done recently in a tertiary hospital. (11)

The top indication for dialysis was uremic encephalopathy followed by Hyperkalemia. In contrast, other literature from Africa in general and Ethiopia, in particular, showed that it was rather the refractory fluid overload which is the commonest indication for dialysis followed by uremic symptoms and signs $(11,17)$

This study showed uremic encephalopathy, hyperkalemia and sepsis significantly predicted mortality for patients with AKI. A study done on Sudanese patients was analyzed with binary logistic regression to identify independent predictors of mortality among AKI patients; Mortality is significantly associated with the increase in patients' age, presence of chronic liver disease, and the severity of AKI as per the KDIGO staging. (12)

Those AKI patients with underlying CKD had not shown to have decreased in-hospital survival. This corresponds with other studies including the one which was done by walker and associates which even showed that there was lower in-hospital mortality of AKI patients with underlying CKD as compared with patients without CKD who develop AKI.(17)

\section{Conclusion}


As sepsis was the dominant cause of AKI as well as mortality predictor and cause of lower hospital survival, early initiation of antibiotics in the Emergency unit would be beneficial to improve the in-hospital outcome of patients with AKI.

\section{Abbreviations}

AKI - Acute Kidney Injury

AGN - Acute Glomerulonephritis

AOR - Adjusted Odds Ratio

ATN - Acute Tubular Necrosis

$\mathrm{Cl}$ - Confidence Interval

CKD - Chronic Kidney Disease

CRS-1 - Cardiorenal Syndrome Type I

COR - Crude Odds Ratio

DF - Degree of Freedom

KDIGO - Kidney Disease Improving Global Outcomes

LOS - Length of Hospital Stay

SD - Standard Deviation

SE - Standard Error

TASH - Tikur Anbesa Specialized Hspital

USA - United States of America

\section{Declarations}

\section{Ethical Approval and Consent to Participate}

Ethical clearance was obtained from Addis Ababa University, College of Health Sciences Institutional Review Board. Patient consent was taken before collecting each individual's data. The patients' data were recorded only by the data collectors and the final combined data were accessible only to the principal investigator and authors. The information summarized is not discussed referring to the patient's name. 
Not applicable

\section{Availability of Data Materials}

The datasets used and/or analyzed during the current study are available from the corresponding author on reasonable request.

\section{Competing Interests}

The authors declare that they have no competing interests

\section{Funding}

None of the authors received any form of funding from any organization for conducting this study.

\section{Authors' Contribution}

MK was the principal investigator who did the conceptual framework and oversaw the research project. $\mathrm{He}$ also did the majority of the data collection analysis and interpretation. BB was a significant contributor in preparing the manuscript and reviewing several drafts of the research. AS, AT, and TA took part in data analysis and interpretation.

\section{Acknowledgments}

We are very much grateful for all the help and support we got from the nurses and all the staff at the outpatient department of the unit of Hematology. We would also like to appreciate the staff at the hospital's Patient Chart record room for the dedicated service we got during the data collection process. We are also very much thankful for all the support and understanding of our patients with whom we needed to communicate while conducting this study.

\section{References}

1. Lameire NH, Bagga A, Cruz D, De Maeseneer J, Endre Z, Kellum JA, et al. Acute kidney injury: an increasing global concern. Lancet. 2013;382(9887):170-9.

2. Dlamini TAL, Heering PJ, Chivese T, Rayner B. A prospective study of the demographics, management and outcome of patients with acute kidney injury in Cape Town, South Africa. PLoS One. 2017;12(6):e0177460.

3. Lewington AJ, Cerdá J, Mehta RL. Raising awareness of acute kidney injury: a global perspective of a silent killer. Kidney Int. 2013;84(3):457-67.

4. Mehta RL, Cerdá J, Burdmann EA, Tonelli M, García-García G, Jha V, et al. International Society of Nephrology's 0by25 initiative for acute kidney injury (zero preventable deaths by 2025): a human rights case for nephrology. Lancet. 2015;385(9987):2616-43. 
5. Susantitaphong P, Cruz DN, Cerda J, Abulfaraj M, Alqahtani F, Koulouridis I, et al. World incidence of AKI: a meta-analysis. Clin J Am Soc Nephrol. 2013;8(9):1482-93.

6. Naicker S, Aboud O, Gharbi MB. Epidemiology of acute kidney injury in Africa. Semin Nephrol. 2008;28(4):348-53.

7. Cerdá J, Bagga A, Kher V, Chakravarthi RM. The contrasting characteristics of acute kidney injury in developed and developing countries. Nat Clin Pract Nephrol. 2008;4(3):138-53.

8. Lunyera J, Kilonzo K, Lewington A, Yeates K, Finkelstein FO. Acute Kidney Injury in Low-Resource Settings: Barriers to Diagnosis, Awareness, and Treatment and Strategies to Overcome These Barriers. Am J Kidney Dis. 2016;67(6):834-40.

9. Adhikari NK, Rubenfeld GD. Worldwide demand for critical care. Curr Opin Crit Care. 2011;17(6):620-5.

10. Kleinknecht D, Jungers P, Chanard J, Barbanel C, Ganeval D. Uremic and non-uremic complications in acute renal failure: Evaluation of early and frequent dialysis on prognosis. Kidney Int. 1972;1(3):1906.

11. Ibrahim A, Ahmed MM, Kedir S, Bekele D. Clinical profile and outcome of patients with acute kidney injury requiring dialysis-an experience from a haemodialysis unit in a developing country. BMC Nephrol. 2016;17(1):91.

12. Osman M, Shigidi M, Ahmed H, Abdelrahman I, Karrar W, Elhassan E, et al. Pattern and outcome of acute kidney injury among Sudanese adults admitted to a tertiary level hospital: a retrospective cohort study. Pan Afr Med J. 2017;28:90.

13. Bagshaw SM, George C, Bellomo R. Early acute kidney injury and sepsis: a multicentre evaluation. Crit Care. 2008;12(2):R47.

14. Bagasha P, Nakwagala F, Kwizera A, Ssekasanvu E, Kalyesubula R. Acute kidney injury among adult patients with sepsis in a low-income country: clinical patterns and short-term outcomes. BMC Nephrol. 2015;16:4.

15. Vandenberghe W, Gevaert S, Kellum JA, Bagshaw SM, Peperstraete H, Herck I, et al. Acute Kidney Injury in Cardiorenal Syndrome Type 1 Patients: A Systematic Review and Meta-Analysis. Cardiorenal Med. 2016;6(2):116-28.

16. Eren Z, Ozveren O, Buvukoner E, Kaspar E, Degertekin M, Kantarci G. A Single-Centre Study of Acute Cardiorenal Syndrome: Incidence, Risk Factors and Consequences. Cardiorenal Med. 2012;2(3):16876.

17. Igiraneza G, Ndayishimiye B, Nkeshimana M, Dusabejambo V, Ogbuagu O. Clinical Profile and Outcome of Patients with Acute Kidney Injury Requiring Hemodialysis: Two Years' Experience at a Tertiary Hospital in Rwanda. Biomed Res Int. 2018;2018:1716420.

18. Naqvi R, Mubarak M, Ahmed E, Akhtar F, Bhatti S, Naqvi A, et al. Spectrum of glomerular diseases causing acute kidney injury; 25 years experience from a single center. J Renal Inj Prev. 2015;4(4):1136.

\section{Figures}




\section{Treatment}

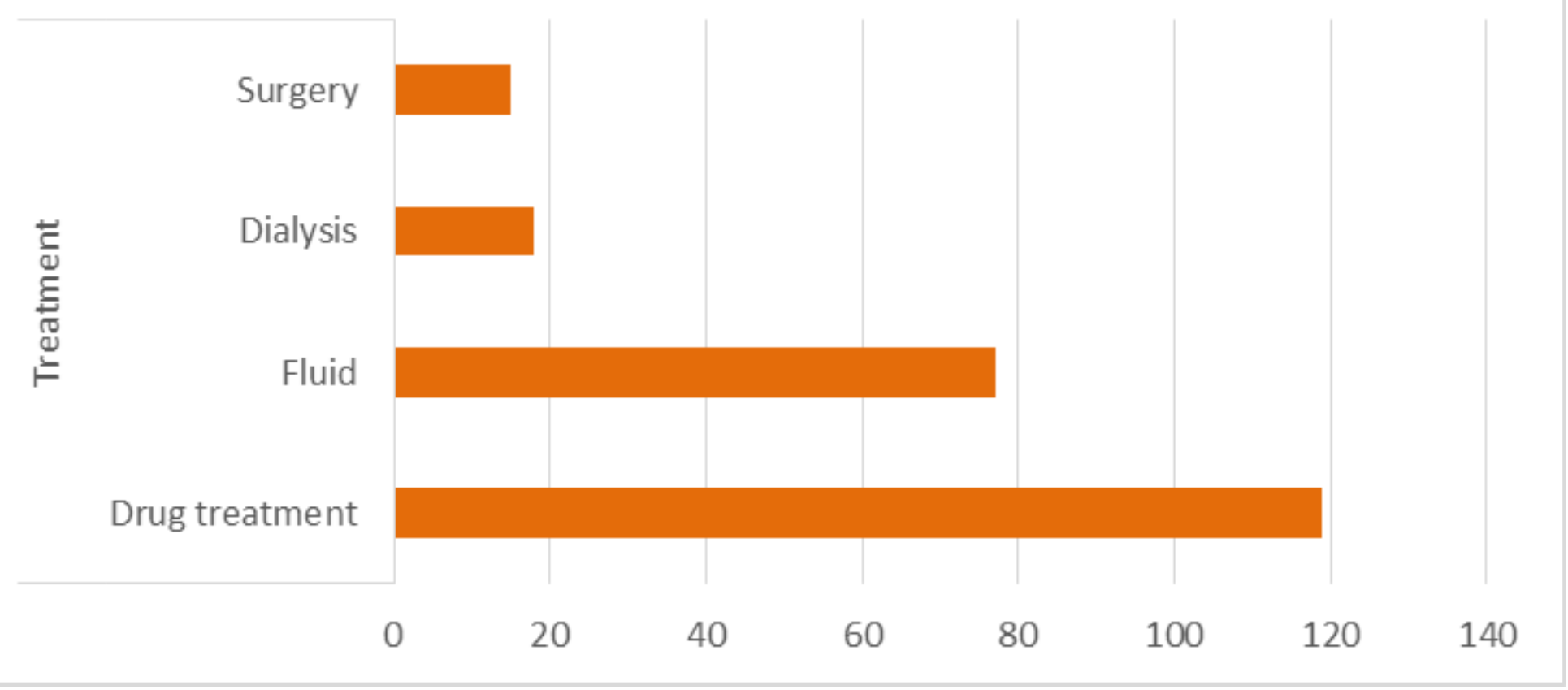

Figure 1

Treatment practice of patients with AKI, TASH, Addis Ababa, 2019 


\section{Disposition}

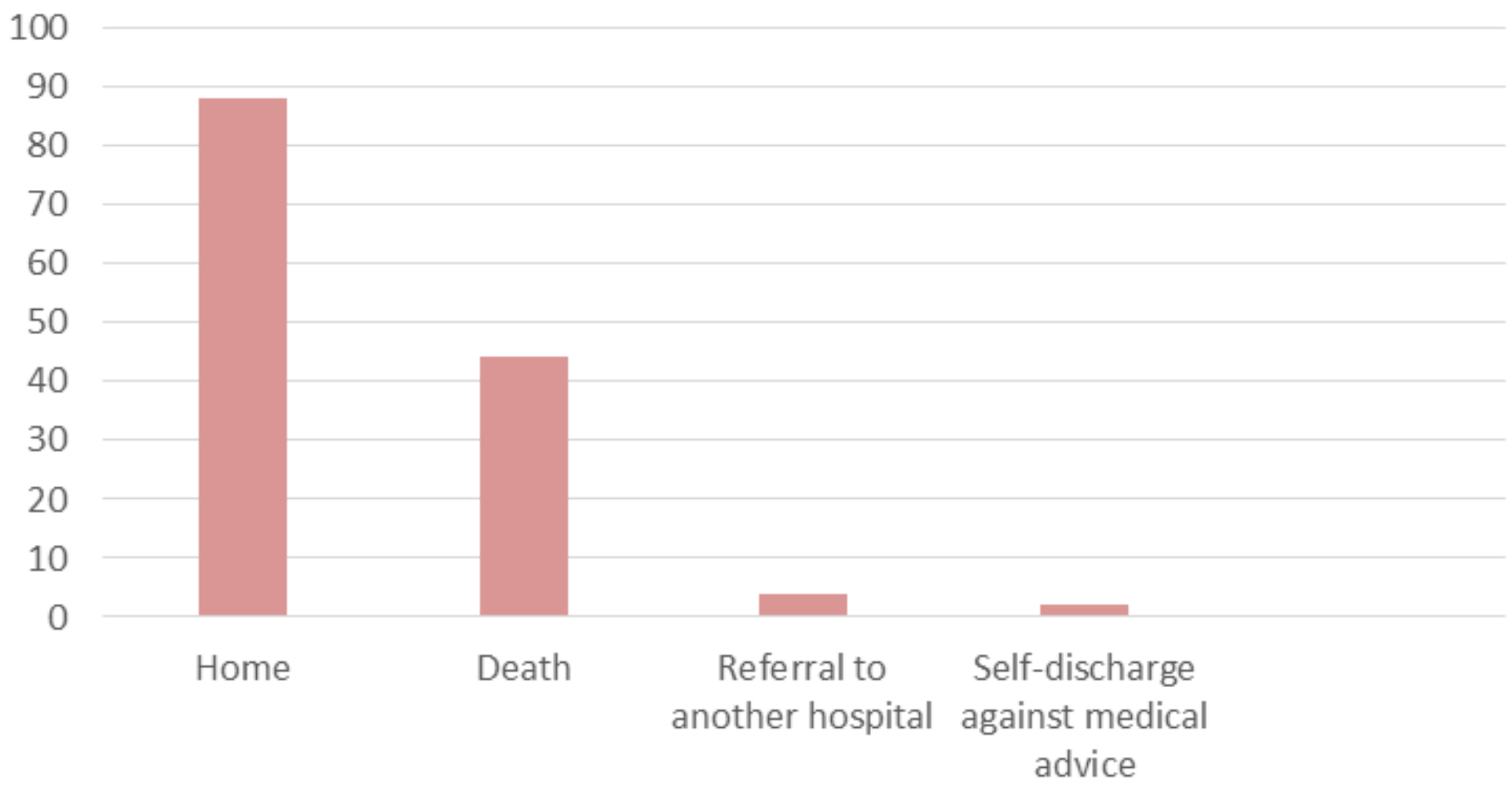

Figure 2

Disposition of patients with AKI, TASH, Addis Ababa, 2019 
$\mathbf{A}$

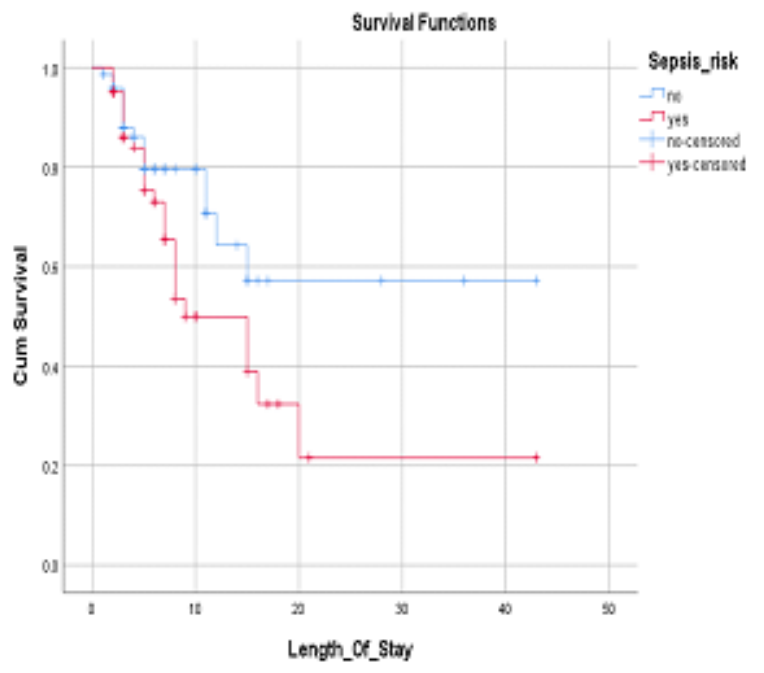

C

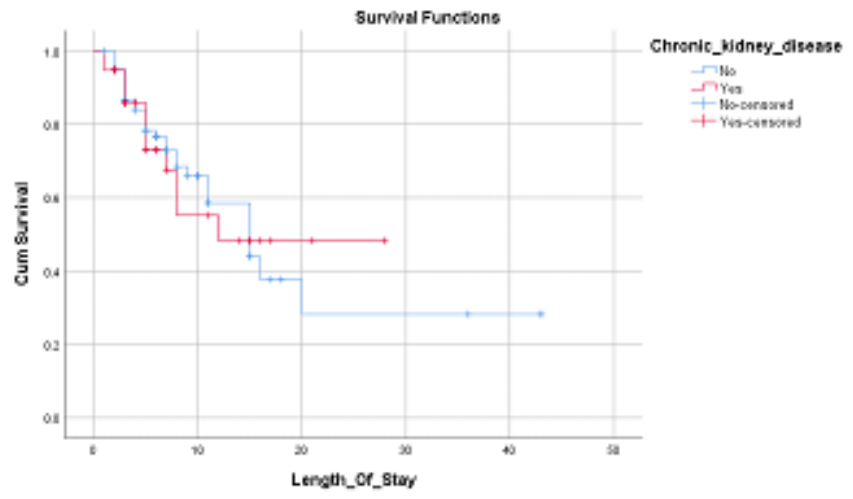

B

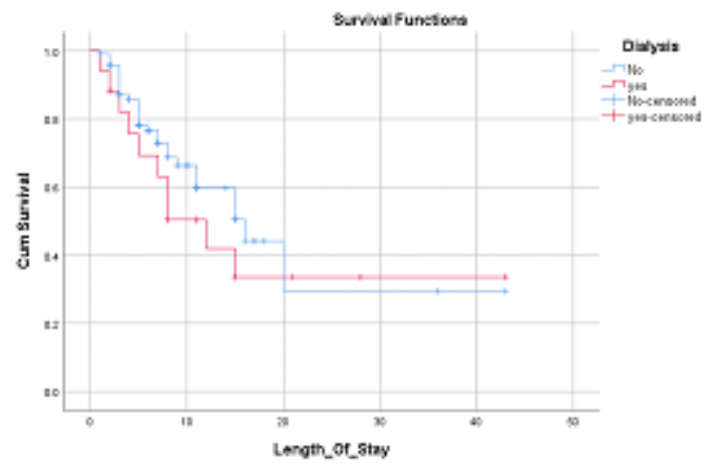

D

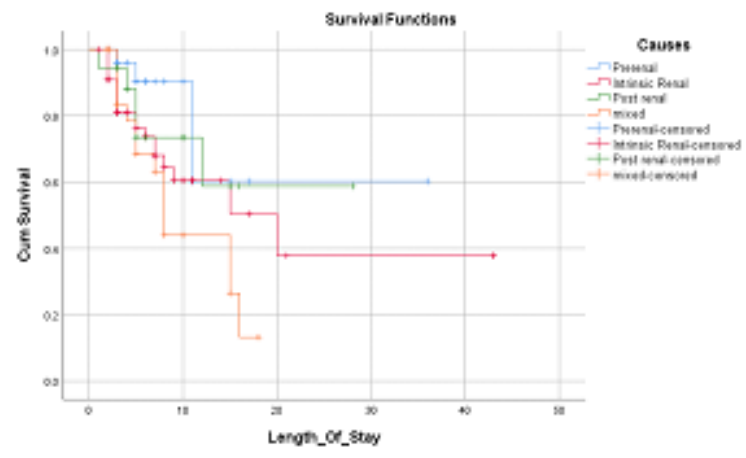

Figure 3

Kaplan-Meier curves A. Time to death in AKI patients with sepsis B. Time to death in AKI patients who underwent dialysis; C. Time to death in AKI patients who had underlying CKD; D. Time to discharge in each type of AKI 